\title{
Abadías Selma, Alfredo / SIMÓN CASTELLANO, Pere (coords.), La prisión provisional y su estudio a través de la casuística más relevante: un análisis ante la segunda revolución de la justicia penal. Atelier, Barcelona, 2020, 368 pp., ISBN 978-84-1824- 417-9.
}

http://dx.doi.org/10.18543/ed-69(1)-2021pp309-317

La obra analiza la figura de la prisión provisional desde el estudio de casos mediáticos en los que - en su gran mayoría - se ha visto aplicada de forma más o menos automática o sobrepasando los límites a los que se halla sujeta. Para ello, la obra reúne a un gran número de expertos que analizan separadamente cada uno de los casos seleccionados al efecto, comenzando, a modo de pórtico, con un conciso e incisivo prólogo del profesor Rodríguez Ramos que puntualiza sobre la necesidad de un cambio de óptica en la aplicación de la prisión preventiva en el proceso penal y advierte del contenido especialmente crítico de los estudios que contiene el libro.

La obra puede estructurarse en tres grandes bloques: un primer bloque dedicado al estudio general de la teoría de la prisión provisional en el que se abordan todas las cuestiones relevantes para la correcta comprensión de la figura en todos sus extremos y vertientes, incidiendo especialmente en los principios, características, presupuestos y especialmente en su evolución legislativa y de la jurisprudencia del TC que desembocó en las últimas reformas de la LECrim en la materia; un segundo bloque dedicado al análisis de la aplicación de prisión provisional en casos mediáticos; y un tercer bloque dedicado a cuestiones que permanecen actualmente abiertas y sobre las que es posible mantener un debate, como la compensación por aplicación indebida y la paulatina incorporación de la dinámica del Law Case anglosajón.

I. El primer bloque comienza con un trabajo del Dr. Pere Simón Castellano, que formula una necesaria introducción teórica sobre los caracteres, principios, aspectos constitucionales y demás cuestiones relevantes que, bajo el prisma de la excepcionalidad, gravitan sobre la necesidad de concurrencia de los presupuestos de fumus boni iuris y periculum in mora, al tiempo que también aborda el procedimiento para su imposición y trata algunos aspectos como el abono de la prisión provisional a la pena haciendo especial 
hincapié en la vertiente penitenciaria, pues la diferencia existente entre preventivos y penados a efectos de beneficios y demás aspectos relacionados con las clasificaciones, con el régimen y con los establecimientos penitenciarios, les genera una desigualdad patente. También aporta algunos datos empíricos que evidencian que España no es el país de la Unión Europea que más presos preventivos tiene, aunque se aprecia una tendencia al alza en los últimos 5 años.

Seguidamente aparece un capítulo especialmente interesante $-\mathrm{y}$ por lo demás emotivo - puesto que se trata de uno de los últimos trabajos que nos dejó el Dr. Vicente Gimeno Sendra, que poco antes de su partida tuvo tiempo de dejar por escrito su visión sobre este importante tema para formar parte de esta magna obra. En su estudio realiza un repaso por la reforma de los arts. 503 y 504 LECrim, así como por los fines, naturaleza, principios, requisitos, fundamentos y presupuestos para su aplicación, recalcando la desaparición por inconstitucional del presupuesto de alarma social, pero reflexionando sobre la pervivencia del presupuesto del riesgo de reiteración delictiva, en especial en el ámbito de la violencia de género y del crimen organizado (con cita de la STEDH de 24-8-1998, ente otras). En ese sentido, termina afirmando la más que dudosa constitucionalidad de esta previsión del art. 503.3 c) LECrim, por cuanto que permite aplicar la prisión provisional siempre que se presuma que el imputado puede actuar contra bienes jurídicos de la víctima cualquiera que sea su gravedad, aspecto que vulnera el principio de proporcionalidad.
En la misma línea argumentativa y ahondando en los contenidos teóricos de la prisión provisional se pronuncia el Dr. Manuel Jaen Vallejo, que aborda la nota de excepcionalidad de la figura en un estudio en el que, partiendo de la difícil armonización entre derecho y sociedad para la correcta comprensión de la función de la prisión provisional en el proceso penal democrático, realiza una aproximación a la regulación de la figura en la Unión Europea y en el derecho comparado, centrando la atención en las llamadas alternativas a la prisión preventiva, que son medidas cautelares no privativas de libertad que igualmente pueden servir a los fines del proceso a los que están destinadas las medidas cautelares personales en su conjunto, aprovechando para resaltar la importancia de los medios electrónicos y tecnológicos para el control y seguimiento de los sujetos sometidos a medidas de control y vigilancia, cuyos obstáculos materiales para su implementación parece que no se hallen presentes en el momento actual, por lo que este autor apuesta por mejorar la justicia penal con estos mecanismos, contando con un adecuado entramado de recursos materiales y humanos para el control y para reaccionar ante los incumplimientos, así como una previsión en materia de protección de datos para salvaguardar la intimidad del sometido a la medida cautelar no privativa de libertad, bajo estos mecanismos de seguimiento que harían innecesaria la aplicación de la prisión preventiva en la gran mayoría de casos en los que ahora se aplica.

Para concluir con este primer bloque, el Dr. Ángel Luis Perrino Pérez 
realiza un estudio sobre el papel del Ministerio Fiscal en el régimen legal de la prisión provisional, pues derivado de los principios acusatorio y de contradicción, la decisión judicial que acuerde la prisión provisional no puede dictarse sin petición de parte, esto es, sin que lo pida el Ministerio Fiscal o la acusación particular y/o popular si las hubiere, siempre que el Fiscal se adhiera o no informe en sentido contrario, pues - de igual modo- el informe del Fiscal oponiéndose a la aplicación de la prisión provisional (favor libertatis) es vinculante para el órgano jurisdiccional, por lo que el papel que juega el Ministerio Fiscal en la imposición de la prisión preventiva reviste un especial protagonismo a pesar de ser - por el momento y hasta que no se lleven adelante las proyectadas reformas en la LECrimsolo una parte. En ese sentido, realiza un recorrido por los fines constitucionales en relación a la intervención del Ministerio Fiscal en defensa de la legalidad y analiza varias circulares e instrucciones de la Fiscalía General del Estado que resultan especialmente relevantes para la compresión de las posturas que el Ministerio Público debe asumir en el proceso penal en virtud de los principios acusatorio y de contradicción, así como el de legalidad, que informan su actuación.

II. El segundo bloque, dedicado al estudio de casos mediáticos, comienza con un trabajo del Dr. Alfredo Abadías Selma, sobre el caso Rosell y Besolí, que titula «entre la ley y el limbo de los justos», donde con una previa relación sintética de casos sonados de personas públicas en las que la prisión provisional ha sido aplicada con distintos criterios, realiza un completo y profundo análisis de los aspectos jurídicos que envuelven a la prisión provisional reforzando los contenidos teóricos, para terminar relatando el caso del ex presidente del Fútbol Club Barcelona, Sandro Rosell y sus socios, entre ellos Joan Besolí, a quienes se acusó de un delito de blanqueo de capitales y otro de pertenencia a grupo criminal, pidiendo elevadas penas de prisión y de multa. Todos ellos fueron absueltos por la Audiencia Nacional, absolución confirmada por la Sala de apelaciones. Lo relevante del caso es que los acusados estuvieron 643 días en prisión preventiva, siendo una de las privaciones de libertad cautelares más largas que se han decretado en España y que han demostrado mayor implacabilidad por parte del Juez instructor encargado de la tramitación de la causa, pues ni siquiera se concedió un permiso de salida al Sr. Besolí cuando su hijo tuvo un accidente de tráfico en el quedó parapléjico, aspecto que viene previsto en el art. 155 del Reglamento Penitenciario con carácter general para penados y en el art. 159 del mismo cuerpo legal para su aplicación a presos preventivos. Lo cierto es que, en el caso de sujetos sometidos a prisión provisional, se aprecia una desigualdad en el tratamiento de los presos preventivos en relación a los penados. Este autor resalta varios aspectos relevantes: por un lado, la depurada y contundente fundamentación jurídica de la sentencia absolutoria en relación a la inexistencia de los delitos por los que se formuló acusación, mediante argumentos que incluso tachan de errónea la acusación de la Fiscalía en relación 
a la comprensión de los elementos que manejaron para construir el relato fáctico sobre el que se sustentó la acusación, extremo que viene a corroborar el exceso en la aplicación de la prisión provisional para los acusados en la causa; y por otro lado, las reclamaciones de indemnización al Estado por los daños y perjuicios que el transcurso en privación de libertad cautelar les ha supuesto, que ascienden a 28.582.950 $€$ en el caso de Rosell, y 2.000.000 € en el caso de Besolí. En este sentido, tras la STC $85 / 2019$, existe un derecho de los privados de libertad cautelar que son después absueltos por cualquier motivo, a que sean indemnizados por el Estado, aunque, termina diciendo este autor, que la exigencia jurisprudencial de que el interesado demuestre el daño efectivamente sufrido en la prisión provisional, sitúa a la sociedad en una suerte de limbo que se presta a la arbitrariedad e inseguridad jurídicas, que se alejan de la verdadera igualdad constitucional y de la unificación de criterios para atender a las exigencias de un Estado de Derecho.

Continúa la obra con un capítulo de la Dra. Gema Martínez Galindo dedicado al caso Lezo, sobre el que añade las notas de automatismo e inconsistencia procesal, pues se trata de una macrocausa por delitos de corrupción en la que los investigados fueron privados provisionalmente de libertad sin la más ínfima concurrencia de los presupuestos sobre los que se basó la resolución judicial para imponerla. Con un relato minucioso del devenir procesal de la causa - vivido en primera persona- narra el debate jurídico mantenido hasta la imposición de la medida cautelar en relación a la paralela mediatización de la causa y los devastadores efectos que todo ello provocó en las vidas y en la salud de los investigados. La decisión tuvo en cuenta, por ejemplo, la ya desaparecida normativamente alarma social como fundamento de la prisión provisional y una genérica afirmación de existencia de riesgo de fuga y de desaparición de pruebas, riesgos eclipsados en el plano de la realidad por imposibilidad material de que existiesen, dada la batería de intervenciones en sus bienes y derechos que ya se habían acordado en la causa. Además, las defensas vieron claramente dificultada su labor dada la naturaleza de los hechos investigados y, en definitiva, se utilizaron motivos populistas con la finalidad de presionar para obtener confesiones y propiciar conformidades. Termina este capítulo con la proyección de un atisbo esperanzador para el proceso, enumerando un gran número de soluciones alternativas a la prisión preventiva que serían de fácil implementación, algunas de ellas ya previstas en las normas vigentes. Finalmente, deja abierta una cuestión en relación a la prevaricación, que debería incluir tanto a quienes solicitan como a los que imponen la medida cautelar injustamente a sabiendas o por imprudencia grave.

Seguidamente aparece un capítulo del Dr. Miguel Bustos Rubio sobre la STC 5/2020, de 15 de enero, sobre el caso Carme Forcadell. Con un detallado relato explica la fundamentación jurídica esgrimida por el TC al resolver sobre cada uno de los motivos de impugnación en el recurso de amparo, que versaron, casi todos ellos, sobre el 
derecho a la libertad del art. $17 \mathrm{CE}$, con extremos hipotéticamente lesivos de ese derecho, como cuando el Juez instructor convocó a las partes a la comparecencia del art. 505 LECrim sin que nadie lo pidiera (a lo que el TC argumentó que lo que no puede es adoptar la prisión preventiva sin que nadie se lo pida, pero puede convocar la vista por propia iniciativa en virtud de sus facultades de dirección). Fueron motivos de impugnación, además, la ausencia de imparcialidad en el juzgador y la vulneración de normas esenciales del procedimiento, motivos todos ellos que, junto los de contenido material sobre la concurrencia de los presupuestos, fueron desestimados, aunque lo relevante es que la STC $5 / 2020$ supone un nuevo ejemplo actualizado para el estudio de la doctrina constitucional en la materia.

Continúa la obra con un trabajo del Dr. Miguel Ángel Cabellos Espiérrez sobre uno de los casos más mediáticos de los últimos tiempos, el caso de la manada, donde el clamor popular y la presión mediática acompañada de una gran politización y de declaraciones incluso de algún Ministro de turno, propiciaron, de entrada, la adopción de la prisión provisional incondicional al inicio del proceso que, paulatinamente, fue flexibilizando su intensidad hacia la posibilidad de eludirse con fianza y la adopción de un gran número de medidas cautelares no privativas de libertad. Esta transformación se produjo en las distintas etapas del proceso, pues tras la primera sentencia condenatoria - con un voto particular discrepante-, se fueron también dictando autos en relación a la situación personal de los procesados que hicieron posible la libertad provisional de los sujetos durante la sustanciación de los recursos, aunque dichas resoluciones contaron también con algún voto particular que se posicionó a favor del mantenimiento de la prisión provisional de todos los condenados en la causa. El trabajo resulta de gran interés por el análisis pormenorizado de todas esas resoluciones, los argumentos de las partes y los votos particulares, proporcionando - desde una óptica crítica - una valiosa información sobre las distintas actuaciones que se llevaron a cabo en este particular proceso.

Siguen trabajos como el del Dr. Sergio Cámara Arroyo que realiza un estudio de casos en relación al internamiento preventivo en el proceso penal de menores, en el que aporta un estudio sistematizado de jurisprudencia sobre la materia que, de forma gráfica y ordenada, permite su fácil manejo y la extracción de la información acerca de los fundamentos esgrimidos en varios casos agrupados según los criterios tenidos en cuenta para su adopción.

El trabajo del Dr. Miguel Ángel López Marchena, narra el error judicial tras la prueba de ADN en el caso Ricardi, que fue acusado de violación y sometido a prisión provisional con la regulación de la LECrim anterior a la reforma que introdujo obligatoriedad de la llamada «vistilla» cuya entrada en vigor se encontraba en periodo de vacatio. De la prisión provisional se dio paso al cumplimiento de la condena, que venía limitada a 30 años de prisión. Pasó 13 años privado de libertad, momento en que se reabrió el caso por nuevas pruebas de $\mathrm{ADN}$ que 
evidenciaban su inocencia, por lo que, tras la revisión, fue absuelto e indemnizado con un millón de euros. El autor realiza un estudio desde una doble óptica: por una parte, desde el relato de casos del sistema norteamericano, donde se aprecia un gran número de de errores judiciales (algunos con pronunciamientos de pena capital) basados en falsos testigos, presiones policiales, reconocimientos erróneos, o incluso por efecto de que los jurados populares son impresionados con imágenes que les proyecta la fiscalía en el juicio oral. Y, por otra parte, se centra en el caso de España, que viene experimentando una media de 6 condenas por año del TEDH en materia de vulneración del CEDH y que suman ya 48 las condenas por vulneración del derecho a un juicio justo.

Por su parte, el estudio que realiza el Dr. Eduardo de Urbano Castrillo versa sobre el caso del ex tesorero del Partido Popular, Luis Bárcenas. Desde una sintética y clara exposición de su conexión con el caso Gürtel, cuenta cómo su situación personal durante la causa fue mutando hasta convertirse en una prisión provisional permanente. Tras la primera sentencia en la que le condenaron a elevadas penas de prisión y a astronómicas multas por varios delitos, le quedaba todavía pendiente el segundo proceso - actualmente enjuiciándose-, por lo que en junio de 2013 se acordó la prisión provisional por primera vez, prolongándose hasta enero de 2015 y volviéndose a acordar en mayo de 2018 , situación que ya no volvió a modificarse a pesar de que fue solicitada en multitud de ocasiones la libertad provisional, siempre rechazada bajo el fundamento de la concurrencia inequívoca de los presupuestos procesales y de las finalidades constitucionales de la medida cautelar, pues se presumía la existencia de patrimonio oculto en el extranjero que no había podido localizarse, y ello acrecentaba el riesgo de reiteración delictiva, así como el riesgo de fuga y de destrucción de pruebas y entorpecimiento grave de la investigación, dada la proximidad del otro proceso en el que se pedían igualmente elevadas penas, por lo que se terminó resolviendo que la prisión provisional se prolongará hasta el 18 de junio de 2033, cuando se cumpla la mitad de la pena impuesta en la primera sentencia. El capítulo detalla minuciosamente cada uno de los autos y sus respectivas motivaciones, que resultan de gran interés por el esfuerzo argumentativo y el elevado numero de cuestiones que se sometieron a consideración respecto a la medida, pues también se trató el estado de alarma por el Covid-19 como fundamento de la libertad provisional (autos de la AN de 26-3-2020 y 8-42020), siendo el motivo rechazado por entender que había más riesgo de contagio - aunque en abstracto - fuera del centro penitenciario que dentro donde se mantiene la normalidad reforzada por los controles sanitarios, limpieza y desinfección; así como que las comparecencias apud acta estaban suspendidas y no sería materialmente posible el control de su libertad provisional. Este autor termina ofreciendo datos sobre la reducción del número de preventivos en España en los últimos años y otros que apuntan hacia que un $90 \%$ de los preventivos son posteriormente condenados, por lo 
que las resoluciones de prisión provisional - salvo casos de carencia de medios en los órganos jurisdiccionales y sobrecarga de trabajo- suelen acordarse con fundamentos sólidos sobre la concurrencia del presupuesto de fumus boni iuris.

El siguiente capítulo de la obra está dedicado a Julian Assange, fundador y redactor jefe de Wikileaks, que estuvo en situación de asilo en la Embajada de Ecuador en Londres, requerido por Estados Unidos y por Suecia. Aunque la permanencia de Assange en esas dependencias era voluntaria, él siempre mantuvo que la situación era forzada porque no podía salir debido a la vigilancia y al riesgo inminente de detención y extradición. Es más, ni siquiera consiguió la seguridad suficiente para viajar a Ecuador a través de un salvoconducto oficial. Reino Unido, por su parte, se resistía a reconocer la situación de asilo otorgada por Ecuador, que le mantuvo recluido en un minúsculo habitáculo londinense policialmente acordonado por las autoridades locales hasta el 114-2019, momento en que Ecuador retiró el asilo y Assange pasó a cumplir prisión provisional a disposición de las autoridades del Reino Unido, que debían decidir sobre la extradición solicitada por Estados Unidos que pretendía procesarle por infracción de una ley de espionaje de 1917 de la que podrían derivarse penas de hasta 175 años de prisión. Lo relevante de este trabajo es la detallada narración de los hechos, previa delimitación espaciotemporal con el fenómeno de Wikileaks como método periodístico de difusión de información veraz, se adentra en cada una de las fases que atravesó el detenido y los fundamentos que se adujeron para tomar las decisiones por parte de los Estados en relación a su situación personal, incluyendo los dos requerimientos de Suecia efectuados en la misma causa: uno que le condujo al país para ser entrevistado por la Fiscalía sueca que desembocó en un sobreseimiento de la causa; y otro que, tras una sorprendente reapertura de ese mismo proceso por una Fiscal diferente, no consiguió la conducción de Assange a Suecia pero sí la entrevista (esta vez en Reino Unido), tras la que se produjo nuevamente el sobreseimiento. Finalmente, se explica con la debida fundamentación, que el Grupo de Trabajo sobre detenciones arbitrarias de la ONU resolvió que la de Assange fue una detención arbitraria.

Por último, aparece un estudio del Dr. Guillermo Ruiz Blay, que versa sobre los casos de Ignacio Morchón y Eduardo Zaplana, en los que, a pesar de la avanzada edad de los investigados y la gravedad de su estado de salud, se dispuso para ellos la prisión provisional. En el primer caso se mantuvo durante casi 6 meses, sin que fuesen acogidos favorablemente los informes médicos aportados a la causa, bajo la premisa de la concurrencia de los presupuestos y la necesidad de avanzar en la investigación, con el añadido de que se argumentó la suficiencia de los pabellones médicos de los centros penitenciarios para tratar sus enfermedades. En el segundo caso, actuando bajo secreto de sumario y con una continua denegación de las solicitudes de libertad provisional dados los informes de los hematólogos que reputaban imprescindibles los 
tratamientos oncológicos fuera del centro penitenciario, el instructor argumentó en el auto que no existen dispositivos de geolocalización suficientes para garantizar el buen fin de la libertad provisional y que el Sr. Zaplana, en su vida diaria, acudía a restaurantes y daba conferencias, por lo que puso claramente en duda el contenido de las periciales médicas aportadas a la causa. En ese orden de cosas, el autor cuestiona la idoneidad del Juez instructor par acordar la prisión provisional, mostrando inclinación hacia el modelo adversarial en el que el Ministerio Fiscal lleva a cabo la instrucción, pero la prisión provisional es acordada por un Juez de garantías que no ha participado en la investigación. El modelo contrario que contiene la LECrim - dice el autorva en contra de la imparcialidad del juzgador, pues al imponer la medida cautelar en un asunto que investiga, queda despojado de ella, aspecto que el autor equipara a la incompatibilidad de funciones entre instruir y enjuiciar, que debe trasladarse igualmente a la prohibición de que quien instruye no puede acordar la prisión provisional.

III. El tercer y último bloque se destina a cuestiones que permanecen abiertas para el debate, como el de los Dres. Rubén Herrero Giménez y David Pavón Herradón, que abordan el aspecto relacionado con la compensación por la privación de libertad cautelar indebida, distinguiendo en el plano teórico entre las dos situaciones de sobreseimiento: el libre y el provisional, con sus respectivos efectos jurídicos. En ese sentido, se realiza un análisis de la doctrina del TC y se ofrecen unas reflexiones sobre la necesaria distinción entre las clases de resoluciones que absuelven o sobreseen la causa, pues parece dudoso que a todas las situaciones que, por definición, no son idénticas, se les atribuya los mismos efectos en relación al derecho a la compensación, por lo que sería lógico reservar ese derecho a las resoluciones que tengan efecto de cosa juzgada. No obstante, se trata de una interpretación que no guarda la debida consonancia con la doctrina del TC que extiende el derecho de compensación -en virtud del principio de igualdad-a todas las situaciones posibles.

Como colofón aparece un trabajo del Dr. Esteban Mestre Delgado, que bajo las notas de hipocresía de la prisión provisional en el caso de la financiación de empresarios por Caja de Ahorros del Mediterráneo, cuenta que tras 15 meses de investigación y con los mismos argumentos que inicialmente sirvieron para la libertad provisional, se acordó la prisión provisional eludible con fianza de 7 millones de euros. Este autor se muestra muy crítico con esta decisión y sus argumentos, pues la asocia a un fenómeno que vive implantado en la función jurisdiccional que descansa sobre una suerte de mala praxis técnica y patológica. En ese sentido, propone atender a criterios de la dinámica del Law Case, del derecho anglosajón, dando cabida a la consideración del precedente combinando los mecanismos procesales para combatir las resoluciones con los aportes doctrinales sobre el estudio de casos.

En definitiva, se trata de un trabajo muy completo, elaborado con el debido rigor académico por parte de 
juristas expertos en la materia, que proporcionan un entramado de información de gran valor teórico, histórico y científico, con importantes aportaciones dogmáticas y una sensible visión crítica sobre la aplicación de la prisión provisional bajo las exigencias - normativas y doctrinales - de un Estado de social y democrático de derecho, que todavía se mantienen notablemente distanciadas del funcionamiento de la institución. Aspecto que se aprecia con mayor claridad cuando se trata de casos mediáticos en los que se produce una suerte de mezcla entre derecho y clamor social que gravita peligrosamente sobre la inseguridad jurídica y la arbitrariedad judicial.

Dr. David Eleuterio Balbuena Pérez Profesor agregado 


\section{Abadías Selma, Alfredo / SIMÓN CASTELLANO, Pere (coords.), La prisión provisional y su estudio a través de la casuística más relevante: un análisis ante la segunda revolución de la justicia penal. Atelier, Barcelona, 2020, 368 pp., ISBN 978-84-1824- 417-9.}

http://dx.doi.org/10.18543/ed-69(1)-2021pp309-317

\section{Copyright}

Estudios de Deusto es una revista de acceso abierto, lo que significa que es de libre acceso en su integridad. Se permite su lectura, la búsqueda, descarga, distribución y reutilización legal en cualquier tipo de soporte sólo para fines no comerciales, sin la previa autorización del editor o el autor, siempre que la obra original sea debidamente citada y cualquier cambio en el original esté claramente indicado

Estudios de Deusto is an Open Access journal which means that it is free for full access, reading, search, download, distribution, and lawful reuse in any medium only for non-commercial purposes, without prior permission from the Publisher or the author; provided the original work is properly cited and any changes to the original are clearly indicated. 